\title{
The Prevalence of Mental Disorders among Serving Soldier Requiring Admission.
}

Namrata Rawal ${ }^{1}$, Praswas Thapa ${ }^{1}$, Yadav Bista ${ }^{1}$.

Department of Neuropsychiatry, Shree BirendraHospital

\begin{abstract}
Introduction: Numerous studies have been done to study the psychiatric conditions in army personnel but none have been done in Nepalese army personnel. The purpose of the present study was to determine the prevalence of common mental disorders among Nepalese Army Personnel who were admitted in psychiatric ward. Methods: Retrospectively 186 case records of Nepalese Army Personnel, who received treatment at the inpatient psychiatric ward over a period of one year (15 $5^{\text {th }}$ May 2010 to $15^{\text {th }}$ May 2011), were included in this study. Descriptive analysis of their demographic data and types of psychiatric disorders was done using SPSS v16. Results: Among the 186 patients who were admitted during the study period, 184 (98.92\%) were male. The most common age range was 21-30 years (70.43\%). The prevalence of the first ten rank of mental disorders among Nepalese Army Personnel were Major Depression (25.27\%), Alcohol dependence (22.58\%), Schizophrenia (14.67\%), Bipolar disorder (8.6\%), Anxiety disorder(6.52\%), Substance induced psychotic disorder(4.35\%), Schizoaffective disorder(3.26\%), Deliberate self harm (2.72\%), Malingering(2.72\%) and Poly substance dependence (2.72). Conclusions: The most common prevalence of mental disorders among inpatient of Nepalese Army Personnel in psychiatric department in the year 2010-11 were Major depressive disorder, Alcohol dependence and Schizophrenia.
\end{abstract}

Keywords: mental disorders, prevalence, army Personnel

\section{INTRODUCTION}

Many investigators have examined the mental health consequences of exposure to war trauma and found substantial postwar psychiatric difficulties among veterans $s^{1-4}$. Various studies on mental disorders in soldiers have been done. For example, a study on the relationship between mental disorders and treatment in US veteran's hospital during 1993-1995, revealed that at least one mental disorder was found in the population studies, of which depression, post-traumatic stress disorder, and alcoholrelated disorders were found at the rates of $31 \%, 20 \%$ and $20 \%$ respectively ${ }^{5-7}$. Another study done in inpatients found alcohol-related disorders as the most common followed by adjustment and personality disorders ${ }^{8-10}$.

In Nepal, the prevalence of common mental disorders had reported only in civilian's population ${ }^{11,12}$. In recent past the incidence of inpatient as well as outpatient psychiatric cases have exponentially increases. A study on common mental disorders in Nepalese army personnel treated as inpatient has never been done; therefore, this study intended to analyze the prevalence of common mental disorders in serving soldiers. Results of the study may be used as basis data in planning for prevention and treatment for Nepalese Army Personnel.

\section{METHODS}

The data was collected from case records of the serving soldiers who received treatment as inpatient at psychiatric ward of the Birendra Hospital from $15^{\text {th }}$ May 2010 to $15^{\text {th }}$ May 2011. All serving soldiers who were admitted in psychiatric inpatient department with a completed psychiatric diagnosis made by psychiatrist, based on the $4^{\text {th }}$ edition of Diagnostic and Statistical Manual of Mental Disorders $(D S M-I V)^{13}$ and $10^{\text {th }}$ revision of International Statistical Classification of Diseases and Related Health Problem $(\mathrm{ICD}-10)^{14}$ were included in this study. Data analyzed were psychiatric diagnosis and demographic information like gender, age, marital status and ranking. The uncompleted records for psychiatric diagnosis were excluded. The data are expressed as frequency and percentage. The prevalence of mental disorders among Nepalese Army Personnel was calculated by gender, rank, age and marital status.

\section{Correspondence:}

Lt. Col. Dr. Namrata Rawal

Dept of Neuropsychiatry, Shree Birendra Hospital

Kathmandu, Nepal

Email:namrata_mahara@yahoo.com

Phone: +977-9841249800 


\section{RESULTS}

Among 186 Nepalese Army Personnel who were treated at psychiatric ward, 184 were males (98.92\%) and only two were females (1.08\%). Majority of patients were between the age group of 21-30 years and 135 (72.58\%) were married. Demographics data were shown in Table 1. The present study revealed that the most common mental disorders was major depressive disorder (25.27\%) followed by alcohol dependence (22.58 \%), schizophrenia (14.67\%), bipolar disorder (8.6\%) and anxiety disorder (6.52\%).

Table1. Demographics data in 186 subjects

\begin{tabular}{|llrr|}
\hline Characteristics of the study population & n & $\%$ \\
\hline \multirow{3}{*}{ Age } & Male & 184 & 98.92 \\
& Female & 2 & 1.08 \\
& $<20$ yrs & 2 & 1.08 \\
& $21-30$ yrs & 131 & 70.43 \\
& $31-40$ yrs & 40 & 21.50 \\
& $41-50$ yrs & 12 & 6.46 \\
Rank & $51-60$ yrs & 1 & 0.53 \\
& Officers & 3 & 1.61 \\
& Warrant Officer & 9 & 4.84 \\
& Private-Sergeant & 154 & 82.80 \\
Marital status & Followers & 20 & 10.75 \\
& Unmarried & 42 & 22.58 \\
& Married & 135 & 72.58 \\
& Separated & 9 & 4.84 \\
\hline
\end{tabular}

The results show that the common three prevalent mental disorders in male were alcohol dependence, schizophrenia and bipolar disorder. For female it was depressive and bipolar disorders (Table 2). Most of psychiatric inpatients were Private and Non commission officer with major depression (25\%) followed by alcohol dependence and schizophrenia as commonest mental disorder in this group of patient. Other mental disorders determined by rank were shown in (Table 3). The most common mental disorders, major depression, alcohol dependence and schizophrenia were mostly found in age group between 21-30 years (Table 4). Most of inpatients were married $(72.58 \%)$. Mental disorders schizophrenia was commonest in unmarried patients in contrast to major depressive disorder in married (Table 5).

\section{DISCUSSION}

The present study revealed that the prevalence of common mental disorders among Nepalese Army Personnel who attended the inpatient psychiatric ward at Birendra Hospital in 2010-11 was similar to the study done in Nepal Medical College and Teaching Hospital in Nepal ${ }^{12}$. The most common prevalent mental disorder found in onother study was major depressive disorder at the rate of $25.27 \%$, which was similar to our study ${ }^{15}$. The study showed that depression rate was found more in male than female and age group between 21-30 years ${ }^{10}$. The possible cause for the difference in our study may be because of case selection we enrolled only the serving sholdier.

Table 2. Distribution of mental disorders by Gender

\begin{tabular}{|lll|}
\hline Diagnosis & n & $\%$ \\
Major dep dis & 47 & 25 \\
Alcohol dependence & 42 & 22.28 \\
Schizophrenia & 27 & 14.67 \\
Bipolar disorder & 15 & 8.15 \\
Anxiety disorder & 12 & 6.52 \\
Substance Induced psychotic Disorder & 8 & 4.35 \\
Schizoaffective disorder & 6 & 3.26 \\
Deliberate self harm & 5 & 2.72 \\
Malingering & 5 & 2.72 \\
Poly substance dependence & 5 & 2.72 \\
Adjustment disorder & 4 & 2.17 \\
Organic brain syndrome & 4 & 2.17 \\
Dysthymia & 3 & 1.63 \\
Personality disorder & 2 & 1.09 \\
Delusional disorder & 1 & 0.55 \\
Total & & \\
\hline
\end{tabular}

Similar to our study, the second most prevalent mental disorder was alcohol dependence in various other studies $^{16-17}$. Most of the alcohol dependent patients were male. This may be because of our custom where females are mostly restricted to consume alcohol. In a study ${ }^{18}$, prevalence of alcoholism in general population in Nepal was $4.5 \%$ which is significantly lower than our study. This signifies that alcohol consuming is a major problem in the army personnel. These findings may provide an opportunity for a development of prevention strategies.

The third most prevalence mental disorder was schizophrenia, mostly seen in privates-sergeants, aged between 21-30 years in unmarried patients. This can be explained from the fact that most privates were around 1820 years old when they undergo recruitment training and in compliance that schizophrenia can be mostly found in men at the age of early 20 years ${ }^{19-21}$. This emphasizes the need of a meticulous selection process and a regular follow up during the training process. Bipolar disorder was found in age between 21-30 years in privates-sergeants.

However, the present study has some limitations. Firstly, this was a retrospective descriptive study. A larger comparative study would provide more comprehensive results. Secondly, the sample size was small as this study focused only on inpatient army personnel. However this forms baseline information for future studies. 
Table 5. Distribution of mental disorders according to Marital status.

\begin{tabular}{|llll|}
\hline Diagnosis & \multicolumn{3}{l|}{ Marital status } \\
& Single & Married & $\begin{array}{c}\text { Sepa- } \\
\text { rated }\end{array}$ \\
Major depressive disorder & 6 & 41 & \\
Alcohol dependence & 3 & 35 & 3 \\
Schizophrenia & 14 & 11 & 2 \\
Bipolar disorder & 3 & 12 & 1 \\
Anxiety disorder & 5 & 7 & \\
Substance Induced psychotic Disorder & 2 & 6 & \\
Schizoaffective disorder & 1 & 4 & 1 \\
Deliberate self harm & 2 & 3 & \\
Malingering & 1 & 4 & \\
Poly substance dependence & 3 & 2 & \\
Adjustment disorder & 1 & 1 & 2 \\
Organic brain disorder & & 4 & \\
Dysthymia & & 3 & \\
Personality disorder & 1 & 1 & \\
Delusional disorder & & 1 & \\
Total & \multicolumn{4}{|c|}{42} & 135 & 9 \\
\hline
\end{tabular}

\section{CONCLUSIONS}

From the present study, it was found that the three most prevalent mental disorders among inpatient Nepalese Army Personnel were major depressive disorder, alcohol dependence and schizophrenia.

\section{REFERENCES}

1. Hoge CW, Castro CA, Messer SC, McGurk D, Cotting DI, Koffman $R L$. Combat duty in Iraq and Afghanistan: mental health problems, and barriers to care. N Engl J Med. 2004;351:13-22.

2. Elder GH Jr, Shanahan MJ, Clipp EC. Linking combat and physical health: the legacy of World War II in men's lives. Am J Psychiatry. 1997; 154:330-6.

3. Koren D, Norman D, Cohen A, Berman J, Klein EM. Increased PTSD risk with combat related injury: a matched comparison study of injured and uninjured soldiers experiencing the same combat events. Am J Psychiatry. 2005; 162:276-82.

4. Wagner AW, Wolfe J, Rotnitsky A, Proctor SP, Erickson DJ. An investigation of The impact of posttraumatic stress disorder on physical health. J Trauma Stress. 2000;13:41-55.
5. Petronis KR, Samuels JF, Moscicki EK, Anthony JC. An epidemiologic investigation of potential risk factors for suicide attempts. Soc Psychiatry Psychiatr Epidemiol. 1990;25(4):193-9.

6. Kessler RC, Borges G, Walters EE. Prevalence of and risk factors for lifetime suicide Attempts in the National Co morbidity Survey. Arch Gen Psychiatry. 1999;56(7):617-26.

7. Hankin CS, Spiro A 3rd, Miller DR, Kazis L. Mental disorders and mental health treatment among U.S. Department of Veterans Affairs outpatients: the Veterans Health Study. Am J Psychiatry. 1999;156:192430.

8. Hoge CW, Lesikar SE, Guevara R, Lange J, Brundage JF, Engel CC $J r$, et al. Mental disorders among U.S. military personnel in the 1990s: association with high levels of health care utilization and early military attrition. Am J Psychiatry. 2002;159:1576-83.

9. Hoge CW, Toboni HE, Messer SC, Bell N, Amoroso P, Orman DT. The occupational burden of mental disorders in the U.S. military: psychiatric hospitalizations, involuntary separations, and disability. Am J Psychiatry. 2005;162:585-91.

10. Creamer M, Carboon I, Forbes AB, McKenzie DP, McFarlane AC, Kelsall $H L$, et al. Psychiatric disorder and separation from military service: a 10-year retrospective study. Am J Psychiatry. 2006;163:733-4.

11. National Mental Health Policy. Adopted by Meeting of Psychiatrists, Psychologists, Representatives of National Planning Commission and Ministry of Health, held on Aswin 5, 2052 (September 21, 1995) at Director General of Health's Office at Teku.

12.PM Singh, L Vaidya, DM Shrestha, R Tajhya and S Shakya.Consultation liaison psychiatry at Nepal Medical College and Teaching Hospital. Nepal Med Coll J. 2009;11(4):272-4.

13. American Psychiatric Association. The diagnostic and statistical manual of mental disorders. 4th ed. Washington, DC: American Psychiatric Association; 1994.

14. World Health Organization. The ICD-10-CM: classification of diseases. 10th rev. Geneva: WHO; 1992.

15. Udomratn P. Epidemiology of mental health problems and psychiatric disorders in Thailand. Songkla: Limbrother Publishing; 2001.

16. Tanchiswad W. Alcoholism: prevalence in general hospital outpatient. J Psychiatric Assoc Thai. 1990;35:3-9.

17. Benjamin JS, Virginia AS. Comprehensive textbook of psychiatry. 8th ed. Baltimore: Lippincott William \& Wilkins; 2003.

18. Thapa M, Sore E. Global mental health in lower and middle income countries: focus on nepal. Presentation at Howard University; 2012.

19. Ripley HS, Wolf S. Long-term study of combat area schizophrenic reactions; preliminary report. Am J Psychiatry 1951; 108: 409-16.

20. Hitschman M, Yarrell Z. Psychoses occurring in soldiers during the training period. Am J Psychiatry. 1943;100:301-5.

21. Gunderson EK, Hourani LL. The epidemiology of mental disorders in the U.S. navy: the psychoses. Mil Psychol. 2001;13:99-116. 
Table 3. Distribution of mental disorders according to Rank

\begin{tabular}{|c|c|c|c|c|}
\hline Diagnosis & $\begin{array}{l}\text { Rank } \\
\text { Officers }\end{array}$ & W/ Off & Pri-Segt & Followers \\
\hline Major depressive disorder & & 1 & 35 & 11 \\
\hline Alcohol dependence & 1 & 3 & 33 & 4 \\
\hline Schizophrenia & & 2 & 23 & 2 \\
\hline Bipolar disorder & 1 & 2 & 12 & 1 \\
\hline Anxiety disorder & & & 11 & 1 \\
\hline Substance Induced psychotic Disorder & & & 7 & 1 \\
\hline Schizoaffective disorder & & & 6 & \\
\hline Deliberate self harm & & & 5 & \\
\hline Malingering & & 1 & 4 & \\
\hline Poly substance dependence & 1 & & 4 & \\
\hline Adjustment disorder & & & 4 & \\
\hline Organic brain disorder & & & 4 & \\
\hline Dysthymia & & & 3 & \\
\hline Personality disorder & & & 2 & \\
\hline Delusional disorder & & & 1 & \\
\hline Total & 3 & 9 & 154 & 20 \\
\hline
\end{tabular}

Table 4. Distribution of mental disorders according to Age.

\begin{tabular}{|c|c|c|c|c|c|}
\hline Diagnosis & $\begin{array}{l}\text { Age } \\
<20 \text { n (\%) }\end{array}$ & $21-30 \mathrm{n}(\%)$ & $31-40 \mathrm{n} \%)$ & $41-50 \mathrm{n}(\%)$ & $\begin{array}{l}51-60 \\
\mathrm{n}(\%)\end{array}$ \\
\hline Major depressive disorder & $1(50)$ & $32(24.43)$ & $12(30)$ & $2(16.67)$ & \\
\hline Alcohol dependence & & $24(18.32)$ & $10(25)$ & $6(50)$ & $1(100)$ \\
\hline Schizophrenia & $1(50)$ & $21(16.03)$ & $5(12.5)$ & & \\
\hline Bipolar disorder & & $12(9.16)$ & $3(7.5)$ & $1(8.33)$ & \\
\hline Anxiety disorder & & $8(6.11)$ & $2(5)$ & $2(16.67)$ & \\
\hline Substance Induced psychotic Disorder & & $4(3.05)$ & $3(7.5)$ & $1(8.33)$ & \\
\hline Schizoaffective disorder & & $5(3.82)$ & $1(2.5)$ & & \\
\hline Deliberate self harm & & $4(3.05)$ & $1(2.5)$ & & \\
\hline Malingering & & $5(3.82)$ & & & \\
\hline Poly substance dependence & & $4(3.05)$ & $1(2.5)$ & & \\
\hline Adjustment disorder & & $4(3.05)$ & & & \\
\hline Organic brain disorder & & $2(1.53)$ & $2(5)$ & & \\
\hline Dysthymia & & $3(2.29)$ & & & \\
\hline Personality disorder & & $2(1.53)$ & & & \\
\hline Delusional disorder & & $1(0.76)$ & & & \\
\hline Total & $2(100)$ & $131(100)$ & $40(100)$ & $12(100)$ & $1(100)$ \\
\hline
\end{tabular}

